
JOAN Millet

Del senyor, 2018

Tècnica mixta 


\title{
Teodor Llorente, traductor i creador
}

\author{
[Teodor Llorente, Translator and creator]
}

\author{
IRENE AtAlaya \\ Universidad de Cádiz \\ irene.atalaya@uca.es
}

Resum: Aquest treball, que pretén englobar-se en la rama històrica dels estudis de traducció, presenta Teodor Llorente com un dels traductors valencians més importants del segle XIX, que sempre va traduir en concordança amb la seua estètica, dedicant-se als poetes més cèlebres del Romanticisme: Hugo, Lamartine, Goethe, Heine i Lord Byron. La seua fama augmentà amb la traducció del Faust el 1882, la primera en vers, i va guanyar la simpatia de personalitats com Menéndez Pelayo, Clarín o Pardo Bazán. També cultivà l'antologia, en la qual va veure el gènere perfecte per a reproduir el seu gust estètic. Les versions de Llorente van tenir un gran impacte en el polisistema literari peninsular i foren reutilitzades per diversos editors i traductors al principi del segle xx. Malgrat que el nom de Llorente semblà quedar relegat a l'oblit durant molt de temps, la visibilitat dels traductors ha de fer-se patent a l'hora de centrar la investigació en la vida, les motivacions i els propòsits d'aquests poetes secrets.

PARAules ClaU: Teodor Llorente, traducció, creació, poesia, segle XIX.

АвstRact: This paper aims to provide an overview of the Valencian poet Teodor Llorente, one of the most important translators of 19th century Spain. He was a poet by choice and translated the work of the most remarkable Romantic authors: Hugo, Lamartine, Goethe, Heine and Lord Byron. He became famous in 1882 with his versified version of Faust, the first to be published in Spain. The reviews were excellent and he earned the support of his contemporaries, writers like Menéndez Pelayo, Clarín or Pardo Bazán. He also cultivated the anthology in translation, and saw this genre as the perfect way to express his aesthetic affinities. His translated poems had an important impact on the Spanish literary polysystem and were reclaimed by many editors and translators at the beginning of the 20th century. Even though the name of Llorente seems to have been forgotten, the translators' visibility must be taken into account, as we look into the life, motivations and goals of these secret poets.

KEYWORDs: Teodor Llorente, translation, creation, poetry, $19^{\text {th }}$ century.

Recepció: Io/O7/2018. Acceptació: I I/O9/20I8. Publicació: I6/I I/20I 8

REVISTA VALENCIANA DE FILOLOGIA / I I (20I8) p. 207-24 I / ISSN 0556-705X DOI I0.28939/RVF.V2I2.45 


\section{Teodor Llorente en la història de la traducció}

Quan acarem l'estudi històric de la literatura, cal tenir en compte les funcions que la traducció ha exercit des d'un punt de vista historiogràfic. Evidentment, a banda d'acostar-nos a obres que sense la seua mediació no ens haurien arribat mai, a causa del desconeixement de l'idioma en qüestió, la traducció també té una funció «pol-linitzadora» (Lafarga \& Pegenaute 2015a: 258), és a dir, d'enriquiment de models literaris mercè al paper essencial dels traductors, que moltes vegades utilitzaren la traducció com a eina estilística, encara que van quedar a l'ombra del procés. No és possible analitzar els moviments ni els corrents estètics en la història de la nostra literatura sense considerar el paper dels agents implicats i, per tant, de llurs creacions i textos o manifests crítics. Darrere les grans obres que estableixen els principis estètics de qualsevol corrent, es troben els traductors que van donar a conèixer els grans autors estrangers en els polisistemes culturals corresponents. Els estudis de traducció, a partir del cultural turn (Bassnett \& Lefevere 1990), han començat a interessar-se pels agents implicats i recentment han aparegut estudis que així ho demostren. Cal assenyalar els treballs de Delisle (1999), Chesterman (2009) i Pym (2009) des d'un pla teòric, i els treballs de Lafarga i Pegenaute (2015b i 2016) pel que fa a la relació autor-traductor al segle XIX.

Francisco Lafarga (1998 i 2000) va ser el primer que es va interessar-se en la tasca de Teodor Llorente com a traductor i, a partir d'aquestes primeres investigacions, l'estudi del personatge en aquest àmbit comença a cobrar protagonisme: especialment pel que fa a la literatura francesa (Lafarga 2001, 2014 i 2016; Ozaeta Gálvez 2006; Atalaya 2016 i 2017b); una traducció de Llorente i Querol de l'anglès, El corsario de Lord Byron (Pegenaute 2015), així com les seues traduccions de Heine (Martino 2011a i 2011b); però també de diversos poemes, d'índole diversa, traduïts al valencià (Roca 2013b). Això no obstant, encara mancava una visió de conjunt sobre la immensa producció traductora de Llorente en castellà — dispersa en la premsa decimonònica i en antologies de natura diversa-, un estudi de la recepció de les seues traduccions, així com

\footnotetext{
* Aquest treball s'ha realitzat dins del marc del projecte d'investigació FFI2015-63478-P MINECO-FEDER.
}

REVISTA VALENCIANA DE FILOLOGIA / I I (20I8) p. 207-24I

IRENE ATALAYA

Teodor Llorente, traductor i creador / 208 
dels vincles entre poesia de creació i poesia traduïda. De tots aquests antecedents va nàixer la idea de la meua tesi doctoral (Atalaya 2017a), que ha tractat, tant com ha estat possible, omplir aquest buit.

Tanmateix, en Teodor presenta una característica pròpia i és el fet que afrontem un personatge polifacètic conegut sobretot pel seu gran valor cultural i literari per a València. ${ }^{1}$ Per tal de donar veu i visibilitzar un traductor de la seua talla, la primera cosa és establir la localització sistemàtica de totes les seues traduccions per a després dividir-les i estudiar-les segons el tipus, a més de focalitzar els comentaris que les obres hagen suscitat en el panorama literari i cultural. Després de conèixer en profunditat la gènesi i el context de les traduccions, es podrà vincular el pensament traductor de Llorente amb el seu concepte de creació.

Teodor Llorente (1836-1911) s'emmotla a la definició de l'«intelectual del XIx [que] no es aún hombre de especialización sino de extensión» (Palenque 1990: 40). L'ofici comodí per a aquest intel-lectual era el periodisme, en el qual també podia fer-se un buit com a crític i donar a conèixer la seua obra. Llorente no solament fou un traductor en castellà, sinó també un poeta en la seua llengua materna i en espanyol, traductor en valencià, per bé que amb una producció poc extensa, historiador, periodista, director de La Opinión, fundador de Las Provincias, propulsor dels Jocs Florals de València i de la societat Lo Rat Penat, senador, diputat i cap del Partit Conservador de València, membre de l'Ateneu de València i gran col-laborador en la premsa cultural nacional i valenciana. A excepció dels pocs anys en què va viure a Madrid, on realitzà el seu doctorat, la figura de Llorente ha estat sempre vinculada a la seua ciutat natal. Com apunta José Iborra Martínez:

Llorente pasó toda su vida en Valencia, pero no perdió nunca la curiosidad por lo que pasaba fuera de ella. Nuestro poeta no se fue oxidando por el paso del tiempo ni por el aislamiento. Por el contrario estuvo atento a las corrientes literarias que nacían en Europa. No fue, pues, un provinciano.

1 Sobre la importància intelectual de Llorente a València, es poden consultar els treballs del Dr. Roca (2004, 2007a, 2007b, 2007c) i les seues antologies poètiques (Llorente 1983, 2013a i 2016).

REVISTA VALENCIANA DE FILOLOGIA / I I (20I8) p. 207-24I

IRENE ATALAYA

Teodor Llorente, traductor i creador / 209 
Espiritualmente nunca perdió la juventud, de lo cual dio muestras [...] en los últimos años (Levante, «Suplemento Valencia», 13.11.1959).

En aquell moment, València era una ciutat en ple apogeu cultural i literari, en la qual Llorente va participar activament, va revaloritzar la seua llengua materna, fou el precursor de la Renaixença i creà un dels periòdics més importants de l'època a escala nacional.

Abans de comentar el corpus traduit, he d'assenyalar que la producció traductora de Llorente pot dividir-se en dos períodes ben diferenciats: una primera etapa que comprèn els anys de 1858 a 1885 o «etapa de joventut», fins a la publicació del seu primer volum de versos valencians; i una segona època, $o$ «darrers anys», que comprèn des del 1904, quan abandona les seues funcions com a director de Las Provincias en mans del seu fill, Teodor Llorente Falcó, fins al 2 de juliol de 1911, data de la seua mort. Els anys d'inactivitat en la traducció coincideixen amb l'etapa política del poeta i la seua consagració a la poesia valenciana. El seu període, com s'aprecia en la bibliografia adjunta, és molt més prolífic, encara que no hi ha dubte que l'empresa traductora de Llorente és, a més de titànica, el projecte de tota una vida, ja que mai no la deixarà de banda, malgrat totes les seues ocupacions. Així mateix, és una tasca realitzada per amor al parnàs europeu, sobretot en la segona època, perquè, amb la seua carrera literària i periodística ja refermada, no necessitava continuar traduint per a veure augmentada la seua fama. També assenyalaré que Llorente no atorga la mateixa importància a totes les seues traduccions. Se sent força orgullós de les seues antologies poètiques: Leyendas de oro, Amorosas i Poetas franceses del siglo XIX i, sobretot, del Fausto i del Libro de los Cantares, per la dificultat addicional de traduir de l'alemany. D'El corsario conserva el record d'un projecte comú amb el seu gran amic, Vicent W. Querol. Zaira i les Fábulas són, segons la meua opinió, un encàrrec editorial, perquè Llorente tradueix La Fontaine en prosa, la qual cosa no concorda amb el seu concepte de traducció poètica. A més, estan desproveïdes de pròleg, mentre que totes les seues obres inclouen aquest tipus de paratext. Un cas diferent és el viatge de la comtessa de Gasparin, Paseo por España, i de Don Jaime I el Conquistador del baró de

REVISTA VALENCIANA DE FILOLOGIA / I I (20I8) p. 207-24 I

IRENE ATALAYA

Teodor Llorente, traductor i creador / 2 Io 
Tourtoulon, perquè ambdues responen a un projecte històric que té com a protagonista la ciutat del Túria.

Llorente assoleix una celebritat sense precedent per a un traductor en el panorama nacional, la qual es desenvolupa alhora que la seua fama com a poeta en valencià en els cercles catalans, mallorquins i provençals. Al mateix temps i des de dos fronts, amb una visió i finalitat distintes, Llorente va promoure, exalçar i ajudar el desenvolupament de la poesia peninsular en castellà i en valencià. En el cas que ens ocupa, sempre que es parla de Llorente en els mitjans nacionals, les al-lusions a les seues traduccions, en especial al Fausto, estan presents, doncs, com apunta Luis Alfonso, «en realidad, la biografía de Teodoro Llorente es más bien bibliografía» (La Ilustración Española y Americana, 20.10.1890). Emilia Pardo Bazán, en l'homenatge celebrat en la premsa amb motiu de la seua coronació a València el 1909, expressa així aquest fet:

[...] casi siempre que se habla del patriarca valenciano se citan, en primer término, las traducciones magistrales con que ha servido y beneficiado a las letras castellanas; y es que hay - aunque parezca extraño- menos traductores excepcionales que poetas. [...] Una traducción maestra es obra de alta cultura, de intimidad del espíritu del traductor con el original, y enriquece un idioma con las recónditas esencias que se creyeron propiedad exclusiva de otro. Yo he oído y he leído que las traducciones de Llorente no carecen de lunares. Por el mismo sabor castizo español que imprime a sus traducciones — cosa digna de notarse—, Llorente ha sido censurado. Hay quien echa de menos en trabajo tan concienzudo como brillante, galicismos, germanismos y giros violentos, de esos que descubren la falta de agilidad del traductor, que no sabe ver en su idioma lo que traslada de otro (La Lectura, 09.1909).

En realitat, Llorente comença a interessar-se en la literatura des de molt jove. Segons el seu besnet, Juan Teodoro Corbín Llorente (2013: 6), el poeta va escriure el primer sonet, "A Clorinda", l'any $1851 \mathrm{i}$ va aprendre el francès a l'escola secundària. Una prova del seu coneixement d'aquesta llengua són els dos poemes que ens va llegar: «Au Prince d'Asturias» (Las Bellas Artes, 1858:

REVISTA VALENCIANA DE FILOLOGIA / I I (20I8) p. 207-24 I

IRENE ATALAYA

Teodor Llorente, traductor $i$ creador / 2 I I 
78) i «À Alphonse de Lamartine», inèdita, que es publica en Lo Rat Penat a la seua mort (1911: 339), bé que data de 1858. Encara que el seu gust per la literatura romàntica francesa s'aferma en els anys de la universitat, el poeta recorda que «mi padre me traía libros que le dejaban sus amigos. Así leí El triunfo de la religión cristiana [...]. Ninguna lectura me había impresionado tanto» (Por esos Mundos, 01.12.1910). La seua amistat amb Marià Aguiló, bibliotecari de la Universitat, i, amb Querol, el seu amic inseparable d'aquells anys, és important per a la seua maduresa artística: «el mayor impulso que recibió la aptitud poética en Llorente, fue su amistad con otro joven de su tiempo, estudiante también de la Facultad de Derecho: Vicente W. Querol» (Navarro Reverter 1909: 387). Això no obstant, fou Antoni Aparisi Guijarro qui el va introduir en la literatura francesa. Es van conèixer després de l'estrena de l'obra teatral de Llorente Delirios de amor, i, a partir d'aleshores, Llorente el visitava al seu despatx, on recitaven versos ensems. Mariano Roca de Togores recorda el jove Teodor «en la calle del Prado, en el sofá del rincón, en diálogo con Aparisi, y leyendo traducciones de Víctor Hugo» (Llorente 2013b: 80). L'any 1858, coneix Pedro Antonio de Alarcón, andalús establert a Madrid, amb motiu de la visita de la reina a València. Alarcón, corresponsal de La Época, venia a cobrir el reportatge. Aquell mateix any, Llorente es desplaça a Madrid per a realitzar els seus estudis de doctorat i allí coneix Ramón de Navarrete i Emilio Castelar. Ambdós, juntament amb Alarcón, van estar relacionats amb la publicació de les seues traduccions d'Hugo. Navarrete és qui les presenta en els cercles madrilenys, i els periòdics La Época i La Discusión comencen a parlar del jove poeta traductor d'Hugo.

Llorente es pot definir com un traductor postromàntic per la nòmina d'autors traduïts, per bé que cronològicament s'allunye del Romanticisme. Aquest període, marcat per una poesia que tracta d'explotar els models estètics, s'estèn des del 1850 fins al 1885 (Pegenaute 2004: 429), justament els anys més prolífics de la traducció llorentina. Hi ha un retorn als models clàssics, en els quals el sentiment segueix vigent, però es rebutja la desmesura romàntica. La força «del buen gusto» continua sent d'actualitat tot i els intents del Romanticisme per a desconfigurar aquesta pauta (Palenque 1990: 200). Al principi del segle, Llorente s'adhereix al parnassianisme, "procedente de Francia y que

REVISTA VALENCIANA DE FILOLOGIA / I I (20I8) p. 207-24I

IRENE ATALAYA

Teodor Llorente, traductor i creador / 2 I 2 
alberga entre sus filas a Gautier, Leconte de Lisle o Baudelaire, propugna el ejercicio del arte por el arte» (Pegenaute 2004: 400), però no combrega amb els decadentistes i modernistes que arribaran més tard. El desfasament en la tria de les seues versions fou criticat en la seua època per figures com Díez-Canedo i, més recentment, per Ricard Blasco (1984).

No obstant això, en Teodor s'engloba dins del reduï, i es podria dir selecte, grup de traductors poètics. Per a ell, la traducció és associada amb la seua carrera com a traductor: ambdues caminen juntes de la mà. No és possible dissociar l'una de l'altra. Les seues primeres temptatives com a versificador estan estretament lligades a la traducció. A més, viu un moment en què aquesta tasca només podia realitzar-la qui fora poeta en la seua llengua pròpia. Per a Llorente, la traducció poètica ha d'entrar en el polisistema espanyol literari sense deixar-se veure, és a dir, sense fer sentir la diferència entre una obra com el Faust de Goethe o una peça clàssica àuria, com El mágico prodigioso de Calderón. Entén la traducció com un procés d'assimilació en què cal esborrar qualsevol indici d'estrangerització i atraure el text vers el lector. Fou, a més, un infatigable traductor des dels seus començaments literaris fins a l'últim alè. El concepte que tenia d'aquest treball, o del traductor poètic, no està marcat per l'espontaneïtat del geni creador romàntic, sinó que es tracta d'una tasca conscienciosa i revisada. Així li explica al Bachiller Corchuelo ${ }^{2}$ el procediment que segueix com a creador o recreador de versos:

Le advierto a usted que yo les tengo horror a los versos que salen sin dificultad, porque creo que la poesía como toda composición literaria debe ser bien pensada, madurada, limada y vuelta a corregir. Odio la facilidad de pluma. [...] Por lo regular, mis poesías, si se publican doce veces, llevan otras tantas correcciones mías (Por Esos Mundos, 01.01.1911).

Aquest comentari, que ja havia estat assenyalat per Rafael Roca (2013a: 83), posa de manifest aquesta eterna insatisfacció poètica, la qual cosa he

2 Pseudònim d’Enrique González Fiol.

REVISTA VALENCIANA DE FILOLOGIA / I I (20I8) p. 207-24I

IRENE ATALAYA

Teodor Llorente, traductor i creador / 2 I 3 
pogut comprovar igualment, pel que fa a la traducció, en la meua tesi doctoral (Atalaya 2017a). Llorente revisa i esmena i, per tant, modifica al llarg de la seua vida les seues composicions: un fet que denota un caràcter perfeccionista $\mathrm{i}$ meticulós. Una prova d'això és el moment en què es posa a la venda el seu poemari de traduccions d'Hugo. Així rememora aquesta primera vivència editorial cinquanta anys més tard:

Recuerdo que la alegría de ver mi primer libro impreso se desvaneció enseguida, pues aparte lo pobre de la edición y la abundancia de las erratas, eran mis versos bastante incorrectos, y comprendí que había hecho mal en darlos a la imprenta (Por Esos Mundos, 01.12.1910).

A banda d'aquest perfeccionisme, una altra característica del Llorente traductor és una certa aurèola d'humilitat, potser a vegades un poc excessiva, perquè es presenta sempre, en els seus textos i entre els coneguts del cercle literari, com un traductor humil que no cerca la popularitat, tal com li confessa a Joan Alcover. Per a ell, només que pocs literaris aprecien les seues traduccions, se sent ja complagut (Llorente 1936: 92). Això no obstant, tot i aquesta falsa modèstia, ell és conscient de la dificultat que suposa el fet de ser traductor de poesia, i del poc reconeixement que se n’obté. Així li ho diu a Balaguer: «todos tenemos flaquezas, la mía es la de ser buen traductor de versos, categoría modesta en la república literaria, pero oficio muy difícil» (Llorente 1936: 119). Es defineix a si mateix com a traductor abans de tot: «Jo no soch poeta, y be ho conech: soch algo pensador, y quan m'ho propose, fas versos, que no estan del tot mal [...]. Per çó me dedique més à traduir versos del[s] verdaders poetes, que à ferlos originals» (carta a Josep Franquesa en Llorente 1936: 222). D'altra banda, també es preocupa per les vendes, l'èxit i el coneixement de les seues traduccions: «mi deseo es que la publicación sea conocida, y para esto basta algo escrito a la ligera, que no le dé trabajo. ¡Se fija tan poco el público en las obras literarias! Hay que recurrir a los reclamos» (carta a Juan Luis Estelrich en Llorente 1936: 193). En les cartes que envia als altres literats, es nota la dedicació que Llorente atorga a les seues traduccions i la preocupació per l'edi-

REVISTA VALENCIANA DE FILOLOGIA / I I (20I8) p. 207-24 I

IRENE ATALAYA

Teodor Llorente, traductor i creador / $2 \mathrm{I} 4$ 
ció d'aquestes. Ja siga per a Montaner i Simon, la Biblioteca Arte y Letras o l'editorial de F. Granada, Llorente segueix tots els preparatius i les proves amb gran rigor, atenció i estima. Per exemple, respecte de l'última antologia que preparava abans de morir i que no va arribar mai a publicar-se, es posa en contacte amb el traductor català Emili Guanyavents i amb Fernández Villegas per a informar-se sobre el procediment que calia seguir pel que fa als drets d'autor vigents a França. ${ }^{3}$

D’altra banda, a més de relacionar-se amb els representants de la Renaixença catalana, valenciana i provençal i amb escriptors d'anomenada en el panorama nacional, Llorente va estar en constant contacte amb altres traductors de l'època que li demanaven consell o traduccions per a incloure-les en diverses antologies, com ara Carlos Fernández Shaw, Guillermo Belmonte Müller, Juan Luis Estelrich o Miguel Sánchez Pesquera, però també amb autors que tradueix, com Balaguer, Verdaguer, Guimerà, Mestres, Collell o els francesos Achille Millien i el baró de Tourtoulon. Fins i tot, si té dubtes sobre certes expressions o girs, fa que aquests arriben als poetes esmentats (cf. en Llorente 1930: 187). No es pot negar que, a hores d'ara, Llorente és, tal com assenyalà José María de Cossío, «el poeta valenciano dedicado con mayor constancia a traer a nuestro idioma los poetas de otras hablas y otras latitudes» (1960: 357), que també va traslladar a la ciutat de València, malgrat l'oblit i la denigració als quals es va sotmetre la seua figura durant molts anys:

[...] gràcies a Llorente es pot dir que València fon una de les primeres poblacions espanyoles incorporada a la sensibilitat lírica universal, i aixina, no foren estranyes en el nostre país les vibracions sentimentals dels esperits del restant del món, ni les característiques de cada gènere i escola [...] i, si el llibreter Mariano de Cabrerizo va obrir les portes de València a la producció romàntica preponderant en les seues tertúlies, Llorente, en la seua influència modificà el sentit del romanticisme valencià (Sala Giner 2011: 180).

3 Sobre aquesta suposada antologia inèdita, cf. Atalaya (2017b).

REVISTA VALENCIANA DE FILOLOGIA / I I (20I8) p. 207-24I

IRENE ATALAYA

Teodor Llorente, traductor i creador / 2 I 5 
Com era pràctica habitual al segle xIx, Llorente comença a publicar les seues poesies, traduccions i originals en la premsa, que té un paper important en la configuració de la recepció de la literatura estrangera a Espanya. La primera manifestació de què tinc constància té lloc l'any 1858 en El Pensamiento de Valencia, periòdic fundat pel ja anomenat Aparisi Guijarro. Es tracta d'una poesia titulada «Bonaparte», que Llorente va incloure en les Meditaciones poéticas de Alfonso de Lamartine..., poemari inèdit. Igualment, la seua signatura apareix en revistes de gran valor literari per a València, entre el final dels anys cinquanta i els seixanta, com Las Bellas Artes o El Museo Literario, però també en La Opinión, periòdic que va dirigir i en què publicà per primera vegada «El corsario» de Lord Byron. ${ }^{4}$ En la premsa madrilenya, el seu nom comença a despuntar el 1859, just abans de la publicació de Poesías Selectas de Víctor Hugo (1860), en el periòdic La Discusión, del qual Alarcón era redactor, on apareix la traducció de «Los infelices» d'Hugo, de La légende des siècles (11.11.1859), i se n'anuncia la imminent publicació.

Malgrat que Llorente siga el creador de Las Provincias el 1866, és cert que, com que es tracta d'un diari públic, les manifestacions sobre la traducció hi són adventícies i ocupen un lloc més destacat en l'Almanaque de Las Provincias, si bé alguns moments d'importància internacional, com ara la mort de Victor Hugo l'any 1885, marquen una fita amb l'aparició d'un suplement replè de traduccions de Llorente en homenatge al gran romàntic. Diem que el valencià no va confeccionar el seu periòdic amb aquest propòsit, encara que sí fou el cas d'una revista de caràcter europeista ara bastant oblidada per la crítica: El Panorama (1867-1872). Mentre Llorente començava a tenir un prestigi a la seua ciutat natal, la seua signatura apareix en els mitjans més reconeguts, com ara La Época, La Correspondencia de España o Los Lunes de El Imparcial, però també en revistes literàries com La Abeja, en la qual Llorente presenta diverses poesies de Goethe i Schiller; Revista Contemporánea o Revista de España; La Ilustración Española y Americana, Germinal o La Diana de Manuel

4 Aquest poema narratiu es va publicar en huit entregues en La Opinión, del 23.08.1863 al 15.11.1863.

REVISTA VALENCIANA DE FILOLOGIA / I I (20I8) p. 207-24I

IRENE ATALAYA

Teodor Llorente, traductor i creador / 216 
Reina. A la fi de la seua vida, quan reprèn la traducció després d'un període marcat per la política, es converteix en l'encarregat de la secció «Parnaso internacional» de La España Moderna per petició expressa del director Lázaro Galdiano, des del 1908 fins a la mort. Per bé que hi haja alguna pinzellada simbolista, som molt lluny, encara que ens trobem al primer decenni del segle xx, de la poesia modernista o d'avantguarda. S'hi aprecia principalment el gust del segle precedent: romàntics i parnassians. Molts dels poemes que hi apareixen estaven previstos per a formar part d'una obra voluminosa, Nueva antología de poetas franceses modernos, que Llorente preparava abans de la seua mort.

\section{Les traduccions en llibre de Llorente}

Les traduccions de Llorente es poden dividir en tres grans blocs: traduccions poètiques d'un únic autor, antologies i altres traduccions en prosa i teatrals. En el primer grup, es poden incloure les Meditaciones poéticas de Alfonso de Lamartine... (1858), que no arribaren mai a publicar-se amb el pròleg d'Aparisi. A continuació, Llorente edita Poesías selectas de Víctor Hugo (1860), un tímid volum que reuneix una col·lecció molt personal de les poesies d'aquell que va ser segurament l'autor més traduït per Llorente. L'obra es va publicar a petició d'Alarcón i l'encapçala un text d'Emilio Castelar, l'únic pròleg halògraf de les traduccions llorentines, ja que a partir d'aleshores ell mateix inserirà sempre l'advertència o el prefaci. Genette (1987: 246) assenyala que aquesta mena de textos amaga una recomanació: «Moi, $\mathrm{X}$, je vous dis qu'Y a du génie, et qu'il faut lire son livre». Castelar, en aquest cas, funciona com un padrí literari. Llorente era conscient de la importància del fet que una personalitat com Emilio Castelar avalara les seues composicions. Això no obstant, aquest s'ocupa poc de la traducció per se i aprofita l'avinentesa per a fer una apologia d'Hugo, que admirava com a polític i pensador. Quant a la selecció dels poemes, el traductor sembla no seguir cap ordre temàtic ni per llibre original. Poesías selectas està dominada per l'eclecticisme més absolut d'un jove poeta-traductor de vint-i-quatre anys. Malgrat que quasi totes les composicions pertanyen a

REVISTA VALENCIANA DE FILOLOGIA / I I (20I8) p. 207-24 I

IRENE ATALAYA

Teodor Llorente, traductor i creador / 217 
Les contemplations, hi ha versions d'Odes et ballades, Les chants du crépuscule, Les feuilles d'automne, Les voix intérieures i Les orientales. Sens dubte, Llorente atorga un espai protagonista als poemes de Les contemplations perquè evoquen el record de l'amor i la felicitat. La càrrega mística i religiosa és també preponderant i el lirisme envaeix tota l'obra, ja que es tracta de poemes dedicats a la filla d'Hugo, Léopoldine, morta prematurament i, potser — pel fet de ser els versos més íntims d'Hugo- Llorente se senta especialment atret per aquells que són dotats d'una connotació política. En aquest poemari, s'adverteix encara el jove traductor inexpert, ja que uns anys més tard reprendrà algunes composicions, com ara «Sara en el baño» (Diversos autors 1906), i millorarà la versificació, fent de la versió un text nou. Per bé que Llorente confesse sentir-se més proper a Lamartine, és cert que sempre va admirar Hugo pel seu amor a la família, al treball, i per els seus dots literaris extremadament prolífics $i$ el lirisme expressat en les seues poesies.

El corsario de Lord Byron és la següent obra literària publicada per Llorente l'any 1863, després de Poesías selectas, seguint un ordre cronològic. Aquesta vegada l'empresa reflecteix en la portada també el nom del seu amic Vicent W. Querol i es va gestar ja des de València. Es tracta de l'única obra completa que Llorente traduí de l'anglès. Aquest text és la manifestació de dos joves amb molt de talent que comencen a experimentar al seu antull amb la traducció. Ambdós amics, que es van conèixer a les aules de la Universitat de València, sentien la mateixa atracció per la poesia i per la traducció i ensems van dur a terme aquest projecte. La correspondència recollida per Roca (2012) i el pròleg del Fausto (Llorente 1882) demostren la relació estreta que mantingueren fins a la mort de Querol en 1889. No és gens estrany el fet que els dos joves s'interessaren en aquest heroi romàntic de temàtica exòtica creat per qui va ser el símbol del Romanticisme anglès. Segons confessa Llorente al Bachiller Corchuelo, van traduir el poema sense saber anglès, "con un diccionario en la mano» (Por Esos Mundos, 01.12.1910) i li'l presentaren a Carolina Coronado, que aleshores estiuejava al Cabanyal, la qual els va animar a publicar-lo. Aquesta traducció és també un treball recreat que supera la llargària del text de Lord Byron (Pegenaute 2015: 139). Així mateix,

REVISTA VALENCIANA DE FILOLOGIA / I I (20I8) p. 207-24 I

IRENE ATALAYA

Teodor Llorente, traductor i creador / 2 I 8 
coincideix amb un estudi que Llorente fa del poeta en El Museo Literario en cinc entregues en 1863, on assenyala la relació entre Byron i Lamartine i entre Childe Harold's Pilgrimage i Le dernier chant du Pèlerinage d'Harold. Encara que no serà un autor de notable importància per a Llorente, el record de Byron apareix al llarg de la seua vida, perquè és la representació de la joventut i de la seua amistat amb Querol.

Això no obstant, l'obra que marca un abans i un després en la carrera de Llorente és el Fausto (1882), la primera traducció en vers que apareix a Espanya. El primer acostament del poeta a l'obra immortal de Goethe té lloc en els anys universitaris, tal com deixa testimoni el mateix Llorente en el pròleg:

En nuestro punzante afán, hallábamos pálidas, desabridas, insuficientes las traducciones españolas o francesas de esos autores, queríamos penetrar más adentro en sus obras fascinadoras, comprender y forzar su sentido literal [...] y cuando veíamos ante nosotros el texto original, aquellas palabras exóticas y enrevesadas, henchidas de sílabas impronunciables, nos provocaban y atraían, [...] nos lanzábamos a descifrar aquellas para nosotros sacratísimas letras. ¿Para qué las gramáticas, empedradas de reglas enfadosas, ni los ordenados vocabularios? Nuestra impaciencia no consentía más que el indispensable lexicón para buscar el sentido de las palabras desconocidas. (Llorente 1882: III)

Aquesta traducció és el treball de tota una vida, ja que fins al moment de la impressió en 1882, Llorente publica, revisita i recrea diversos fragments del Fausto en la premsa. La primera manifestació apareix també en El Museo Literario (16.04.1864): «El prólogo en el cielo». Tal com el mateix Llorente anuncia, s'hi pot observar que, en un principi, el poeta dona a conèixer la seua traducció als mitjans valencians abans de llançar-se a publicar-la en revistes nacionals prestigioses, com ara la Revista de España, que publica per fascicles el passatge «Ante las puertas de la ciudad» (28.04.1873 i 28.05.1873), o la Revista Contemporánea (23.10.1876). Vegeu, a tall d'exemple, un fragment de la total recomposició que va tenir aquesta primera versió respecte de la definitiva.

REVISTA VALENCIANA DE FILOLOGIA / I I (20I8) p. 207-24I

IRENE ATALAYA

Teodor Llorente, traductor $i$ creador / 2 I9 
El Museo Literario (16.04.1864)

Su música une el sol acompasada al de los orbes alternando coro; al ángel vivifica su mirada aunque los ojos quema el disco de oro, y anuncia ya cumplida la jornada El ronco trueno al retumbar sonoro. Bellas, Señor, tus obras todavía son como en el del mundo primer día.
Biblioteca Arte y Letras (1882: 49)

Une su añejo ritmo a la armonía de la celeste esfera el sol sereno, y exacto sigue la prescrita vía con los potentes ímpetus del trueno. Al Ángel da vigor su llamarada, aunque no puede penetrar en ella: como al salir sonriente de la nada, aún es la obra de Dios sublime y bella

Després d'aquesta lectura, es podria deduir, si no sabérem que es tracta del mateix traductor, que estem davant dues traduccions completament diverses, realitzades per poetes distints. Llorente canvia la rima de l'hendecasíllab, encara que manté la rima consonant i la mètrica. La publicació de 1882 fou encarregada per la Biblioteca Arte y Letras, guarnida de belles il-lustracions. Això no obstant, Llorente s'encerteix abans que Valera, que havia traduit amb un enigmàtic Guillermo English la primera part en prosa de l'obra, no pensava continuar el llegat amb una versió en vers (Llorente 2013b: 128). Conscient de la empresa que està a punt d'escometre i de les conseqüències que poden ocasionar-li una traducció no reeixida, en el pròleg, Llorente s'hi presenta davant el lector com un "humilde traductor», la qual cosa pertany a la retòrica captatio benevolentiae. Ja havia utilitzat aquesta estratègia abans, en les seues antologies poètiques. La «carta que puede servir de prólogo para esta traducción» va adreçada a Querol, i no al lector, perquè «decídome al fin, querido Vicente: cedo a tus instancias y a las de otros buenos amigos. [...] Si hago mal, vuestra será la culpa, aunque solo yo pague la pena» (1882: I). Querol esdevé ací en realitat un destinataire-relais (Genette 1987: 180). Certament, s'hi pot veure com una estratègia del traductor: tan sols hauria concedit a donar el Fausto a l'estampa perquè aquest era el desig dels seus col-legues de gremi. Per a reprendre $\mathrm{i}$ afermar la seua idea de «humilde» traductor, a la fi del pròleg demana als crítics que «me otorguen la merced de decirme [els defectes de la traducció] para corregirlos», i prega a més la seua indulgència perquè no li facen «renunciar a la esperanza de sacarla [la traducció] nuevamente a la luz, limpia de sus manchas» (1882: XXIX).

REVISTA VALENCIANA DE FILOLOGIA / I I (20I8) p. 207-24 I

IRENE ATALAYA

Teodor Llorente, traductor i creador / 220 
Això no obstant, tot i les seues temences, aquesta traducció desperta aviat el furor dels contemporanis. Ací es poden portar a colllació els epitextos, és a dir, l'aparat crític que envolta les traduccions i que és necessari per a conèixer la recepció que van tenir les obres, contextualitza les opinions en el moment històric precís de la seua aparició i és, per tant, el material historiogràfic imprescindible per als estudis històrics de traducció. Respecte dels nombrosos comentaris positius que la traducció de Llorente va generar, Pageard (1958) troba la resposta en el lector al qual es destinava: un públic conservador. Llorente tenia molt bones relacions amb aquests cercles. Aquesta idea es pot vincular a la noció d'habitus literari de Bourdieu, segons la qual la pràctica social es troba al centre del pensament literari. Per tant, la trajectòria social de Llorente, així com els seus contactes en els mitjans periodístics de la Península, tenen un paper essencial en la configuració de l'habitus d'aquest traductor en concret. Això es pot albirar mercè als epistolaris publicats, en els quals es donen a conèixer les relacions personals i professionals del poeta valencià i que demostren aquesta hipòtesi. Mitjans com ara La Época de Madrid, amb el qual Llorente manté una bona relació professional, lloen la traducció en vers. Leopoldo Alas Clarín és una de les grans veus que donen prestigi a l'obra de Llorente en El Progreso (8-10.06.1883), perquè opina que ha prestat un gran servei a les lletres. A més, no és partidari de la traducció en vers quan qui la realitza no és un vertader poeta, però, quan s'uneixen tots els elements necessaris per a produir una bona traducció, apareixen obres com la de Llorente, excel·lent traductor perquè es un «poeta, verdadero poeta». Evidentment, també hi hagué detractors, com el polèmic Pompeu Gener, que, des de París, sosté que la traducció de Llorente no s'ha realitzat directament de l'alemany, i la critica així:

[...] dans le sabbat de la Nuit de Walpurgis, on entend même des seguidillas, comme si on assistait à une fête de paysans des environs de Madrid. Il est fâcheux qu'un écrivain de la trempe de M. Llorente ait employé son talent car il en a à masquer sous ces strophes espagnoles la pensée philosophique de Goethe (Le Livre, 10.06.1883).

REVISTA VALENCIANA DE FILOLOGIA / I I (20I8) p. 207-24I

IRENE ATALAYA

Teodor Llorente, traductor $i$ creador / $22 \mathrm{I}$ 
És evident que Llorente no dominava l'alemany i que va traduir fonamentant-se en les traduccions que existien en italià o francès, la de Maffei o la de Nerval, i amb l'ajut de gramàtiques i diccionaris. Una prova d'això és la traducció del Libro de los Cantares de Heine (1885) que tradueix en un tàndem literari amb el jove valencià Arturo Lliberós (cf. en Atalaya 2017a: 197-200). Miquel i Badia, des del Diario de Barcelona (12.12.1883), li retrau que Faust parle "como un caballero español de capa y espada» i que Mefistòfil s'expresse com un dels «maléficos personajes [...] de nuestras tragicomedias», a la qual cosa Llorente donarà resposta en el pròleg de les poesies de Heine. Allò clar és que les crítiques i els comentaris positius són molt més abundants que dos casos negatius aillats i que Llorente s'eleva en aquest moment al grau de «traductor de autoridad» (Peña Martín 1997: 36). La dificultat de l'empresa duta a terme per primera vegada en la història de la literatura espanyola el converteix en un referent per a la cultura de aquell moment. Cada vegada que se cita el Fausto, siga com a obra literària, o en els seus vessants operístics o teatrals, s'al-ludeix a la traducció de Llorente o se'n reciten els versos. Igualment, al llarg de la resta del segle seguiran apareixent fragments traduïts en les revistes i l'obra serà reeditada a Espanya i a Amèrica Llatina.

Dos anys després d'aquesta fita literària, Llorente es llança amb la traducció del Libro de los Cantares per a la mateixa Biblioteca, que serà igualment lloada pels contemporanis, especialment per Menéndez Pelayo i Pardo Bazán. Com en el cas anterior, Llorente manté la mateixa tàctica, és a dir, la de publicar esbossos en premsa, en la Revista Contemporánea, Día de Moda o La Diana, i a més continua el llegat de Florentino Sanz, l'introductor de Heine a España, amb la publicació de la primera traducció completa d'aquesta obra de Heine. El llarguíssim pròleg, de més de cinquanta pàgines, no és sinó una declaració d'intencions, en la qual el poeta justifica la seua traducció i respon a la crítica de Miquel i Badia:

Una traducción en verso no puede ser más que una aproximación a la obra traducida; puede quedar el traductor a cien leguas de ella; puede acercarse mucho, pero nunca bastante para cumplir completamente su

REVISTA VALENCIANA DE FILOLOGIA / I I (20I8) p. 207-24I

IRENE ATALAYA

Teodor Llorente, traductor i creador / 222 
propósito. Hay también diversas maneras de hacer estas traducciones, desde la imitación y la paráfrasis, que solo toma los pensamientos capitales del autor para darles expresión distinta, basta la traducción ceñida y literal, que adopta la misma forma métrica del original y sigue su frase y su dicción, en cuanto es posible (Llorente 1885a: XLIX-L).

Aquestes traduccions de Llorente són coetànies de les del veneçolà Pérez Bonalde, qui també tradueix El cancionero de Heine (1885). És curiós conèixer els intríngulis literaris que tenien lloc aleshores i les crítiques pronunciades a favor de l'un i de l'altre respecte de les traduccions, ja que Juan Fastenrath, amic de Llorente, realitza el pròleg per a les les traduccions de Pérez Bonalde (Atalaya 2017a: 194-197). Llorente se sent inquiet per aquesta nova publicació i li'n sol-licita de seguida una còpia, per a comparar-la amb la seua, a Querol, que per aquell moment ja residia a Madrid. També en demana el veredicte a Menéndez Pelayo, el qual es decanta per la seua traducció i, d'aleshores ençà, la relació entre ambdós es referma i es desenvolupa en el temps fins al cobejat pròleg del Nou llibret de versos (1909). ${ }^{5}$

En la seua segona època, en 1905 hi ha una segona edició del Fausto revisada que afegeix un resum de la segona part, perquè com confessa a Menéndez Pelayo no s'atreveix a dur a terme aquest projecte. En tornar a acarar la traducció de la primera part, sent la necessitat de revisar-la i aclarir-ne alguns passatges i, a tal efecte, demana ajuda a Fastenrath i compara les diverses versions espanyoles, italianes, portugueses i franceses per a uns versos del «Pròleg en el cel». De la mateixa manera, revisita les seues traduccionsde Heine en 1908 i aboca el cicle d'El Mar del Norte y el Romancero per a l'editorial barcelonina F. Granada. Algunes d'aquestes versions ja havien aparegut en l'Almanaque de Las Provincias (1880) i en la Revista de Valencia (1883). En aquest moment, Llorente és ja un traductor consagradíssim i aquesta nova edició serà objecte de nombroses crítiques i comentaris molt elogiosos.

5 A aquest efecte, cf. el treball de Roca (2013a).

REVISTA VALENCIANA DE FILOLOGIA / I I (20I8) p. 207-24I

IRENE ATALAYA

Teodor Llorente, traductor i creador / 223 
El següent gran bloc de traduccions el constitueixen les antologies. Aquest gènere literari serà el predilecte del poeta, ja que pot donar una mostra molt personal d'un gust estètic particular. Tanmateix, l'antologia és l'expressió d'una consciència crítica literària en un moment històric precís. En 1875 apareix Leyendas de oro i a l'any següent Amorosas. Més tard, en la segona època, edita les seues Poetas franceses del siglo XIX i la seua segona sèrie de Leyendas de oro. Totes, tret de Poetas franceses, inclouen autors de diverses latituds. La segona sèrie és important, perquè Llorente introdueix, per primera vegada, autors en llengua catalana i apareixen grans noms com ara Maragall, Verdaguer, Guimerà $^{6}$ o Alcover, encara en 1878, Llorente, a petició expressa de Balaguer, ja havia traduït una de les seues Tragedias, «La muerte de Aníbal» (1878: 6582), en vers castellà per a la segona edició (cf. Llorente 1928: 33). De Leyendas de oro, n'hi hagué quatre edicions. De la tercera edició, n'hi ha dues versions diverses amb selecció i editor diversos: una selecció promoguda per Pascual Aguilar, al final dels anys vuitanta, que aleshores havia agafat les regnes de la Biblioteca Selecta, en la mateixa línia que les dues precedents; i una altra pel mateix Llorente en 1879. Amorosas (1876) també va gaudir d'una bona recepció amb tres edicions. Aquestes dues antologies són d'ordre temàtic i hi ha composicions d'Hugo, Lamartine, Heine, Schiller, Goethe, Uhland, Longfellow i Lord Byron. Per tant, abans de llançar el seu Fausto, Llorente ja era conegut com a antòleg. Manuel Cañete escriu una crítica per a la Revista Europea, que Llorente, absolutament afalagat, inclou en l'edició de 1879. A més, el crític assenyala la forma de traducció de Llorente:

Esta libertad, que le lleva más de una vez hasta el límite donde la traducción se convierte en paráfrasis, era en algunos de los poemitas que denomina Leyendas de oro punto menos que ineludible, so pena de despojarlos por completo de su natural atractivo (Revista Europea, 15.07.1875).

6 Les traduccions d' «El arpa», de Verdaguer, i «Ultratumba», de Guimerà, ja havien aparegut en La Ilustración Española y Americana (15.01.1889) i en La España Moderna (05.1892), respectivament.

REVISTA VALENCIANA DE FILOLOGIA / I I (20I8) p. 207-24I

IRENE ATALAYA

Teodor Llorente, traductor i creador / 224 
Com era previsible, el poeta va modificar i va revisar les versions en les diverses edicions. L'última de les edicions, de 1908, ja inclou dos parnassians: Mendès i Coppée. La segona sèrie, que aparegué al mateix temps que la quarta edició, està dominada per l'eclecticisme, ja que s'hi barregen romàntics, parnassians francesos i alemanys i la següent novetat:

[...] la de haber yo traducido al castellano, para incluirlos en ellas, versos de autores que no son extranjeros para nosotros, pero que tienen idioma propio, distinto al nacional de España. Me refiero a la brillantísima pléyade de vates catalanes, gloria del renacimiento de que se enorgullece el antiguo Principado. Fuera de él, en nuestra misma patria, no son tan conocidos ni tan apreciados como merecen, y esto ha contribuido a mi propósito de presentar algunas de sus poesías vestidas a la castellana (Llorente 1908: v).

En el moment d'aquesta publicació, Llorente ja és un autor consagrat en les lletres valencianes $i$ ha publicat diversos volums amb les seues poesies originals. En traduir els autors catalans, evidencia la necessitat de donar-los a conèixer en la resta del país. En 1908, el valencià és un traductor celebèrrim i és conscient que està afavorint l'entrada d'allò que seria considerat com a literatura perifèrica, seguint la teoria dels polisistemes, en la literatura que ocupa, per raons històriques, una posició central. De caràcter totalment eclèctic i amb una motivació merament estètica, hi ha també representants del Romanticisme, Musset, Hugo o Vigny, o del parnassianisme, Coppée o Sully Prudhomme, per la qual cosa se'n pot assenyalar el caràcter històric, ja que són poemes del segle passat.

Poetas franceses del siglo XIX (1906) és l'última de les antologies de Llorente publicada en la Biblioteca Universal de la prestigiosa editorial catalana Montaner i Simon i es decanta al final de la vida envers la poesia francesa, fet que es confirma amb l'obra que Llorente preparava abans de la seua mort, Nueva antología de poetas franceses modernos. Es tracta clarament d'una antologia històrica al gust perquè hi ha representants del Romanticisme, algun

REVISTA VALENCIANA DE FILOLOGIA / I I (20I8) p. 207-24 I

IRENE ATALAYA

Teodor Llorente, traductor $i$ creador / 225 
simbolista com Verlaine, certes pinzellades de Baudelaire i parnassians com Sully Prudhomme i Coppée. Ens trobem davant el projecte antològic llorentí més ambiciós, que compta amb 376 poemes escrits per 47 poetes, dels quals vint seguien vius, encara que, tret de Rostand, el més jove de la nòmina, són tots precedents o pertanyents a la generació de Llorente, i moriran durant el primer terç del segle xx. Aquesta obra és una retrospecció envers la seua joventut en què repassa els seus primers contactes amb la literatura francesa i les seues primeres traduccions i publicacions. D'alguna manera, es justifica davant el públic per l'antologia que presenta. Hi explica que es tracta dels «amors de la joventut» (Llorente 1906: 6) que s'han remogut en la vellesa. Conscient que la seua tria pot produir rebuig, perquè poden acusar-lo de certes absències majors, Llorente s'avança a les possibles crítiques en el seu pròleg al-ludint a la mateixa idiosincràsia de la traducció poètica: «quizás algún lector eche de menos en esta galería de ingenios esclarecidos, otros que también son muy nombrados; pero he de advertir que no todos los versos se prestan a buena traducción rítmica» (1906: 9). Baudelaire, ensems a Verlaine, són les úniques mostres que hi ha de simbolisme incipient. No obstant això, Llorente justifica la seua tria explicant al lector que «las composiciones [de Baudelaire] para este libro son de las que no pueden censurarse por su desconsolador pesimismo o por sus tétricas lobregueces» (1906: 392); de Verlaine apunta també en la mateixa línia que «son de las que menos quebrantan las leyes estéticas, que el autor quiso desconocer» (1906: 396). Les crítiques a aquesta obra tan allunyada dels corrents estètics del moment es reprodueixen en vida del poeta, però també a finals del segle xx. Ricard Blasco, qui en realitat amaga un judici politicolingüístic, perquè retrau a Llorente no haver traduït al valencià, també critica aquest aspecte, és a dir, «l'absència» de certs poetes, així com la seua lenta evolució poètica:

No solament no assimilà els «poètes maudits» francesos [...] tan llunyans del seu tarannà conservador. Tampoc no va entendre quina cosa era el simbolisme, ni encara menys en què derivà a partir de 1895 . Fort de la seua destresa tècnica, no canvià en res l'estil de versificar, igual en cinquanta anys que el primer dia. (Blasco 1984: 48)

REVISTA VALENCIANA DE FILOLOGIA / I I (20I8) p. 207-24I

IRENE ATALAYA

Teodor Llorente, traductor i creador / 226 
No em sembla, tanmateix, una crítica pertinent ja que una antologia està dominada pel gust estètic d'aquell que la compon i, en conseqüència, proposa ineludiblement les seues tries i models. En el cas del poeta valencià, aquests models són clarament subjectius, però cal preguntar-se quina antologia no ho és. No obstant això, Blasco es contradiu quan matisa que efectivament «tota antologia transparenta el gust i les inclinacions de l'antòleg» i que la de Llorente no s'escapa a aquesta regla (1984: 50). Tampoc el valencià «dissimula ni afinitats ni antipaties, com no les amaga a l'hora d'antologar poetes o traduir-ne poemes» (Blasco 1984: 51). Allò cert és que Llorente, ens agrade o no, fou sempre fidel a una ètica que es traduïa en la seua poètica, tant com a creador de versos propis com pel que fa als aliens. Pardo Bazán explica magistralment la tria duta a terme per Llorente:

Algo de preferencia por Víctor Hugo y Lamartine noto en esta antología; ¿cómo extrañarlo? Son [...] los amores de la mocedad del poeta; son los primeros que encantaron sus horas. [...] Los poetas que nos llegan adentro son siempre los que se adueñaron de nosotros en la juventud, los que nos desfloraron la fantasía (Cultura Española, 08.1909).

En el tercer grup de traduccions, les que podríem considerar menors, totes corresponents a la primera època, es troben tres obres en prosa i una obra de teatre en vers. Es descarta la motivació estètica per a traduir-les, encara que es pot considerar que Don Jaime I el Conquistador (1874) i Paseo por España (1875) guarden una estreta relació amb una altra de les passions llorentines, és a dir, València. Zaira de Voltaire (1868) i Las Fábulas de La Fontaine (1885) són segurament un encàrrec editorial: la primera, per a la col·lecció dirigida per Cayetano Vidal Teatro selecto, antiguo y moderno, nacional y extranjero, i la segona, per als editors Montaner i Simon. Quan Llorente es refereix a les seues traduccions en les diverses semblances o entrevistes biobibliogràfiques, no en farà menció específica. Tampoc n'hi hagué un reconeixement per part de la crítica i els paratextos són escassos o, fins i tot, inexistents. Tot i això, el seu interès ha de ser considerat en la producció intel-lectual de Llorente, es demos-

REVISTA VALENCIANA DE FILOLOGIA / I I (20I8) p. 207-24 I

IRENE ATALAYA

Teodor Llorente, traductor $i$ creador / 227 
tra així que només alguna estranya vegada, en va traduir algun desvinculat de la seua concepció de la traducció poètica.

Zaïre és l'obra teatral més coneguda i traduïda de Voltaire. Llavors, Llorente havia encetat una bona relació amb els cercles catalans gràcies als Jocs Florals de Barcelona de 1868 (Roca 2007b: 177). Fins aleshores, sobreeixia la traducció de García de la Huerta, però els editors decideixen incloure la versió de Llorente «el distinguido publicista y aplaudido poeta valenciano» (Voltaire 1868: 599) i no recuperar traduccions anteriors ja publicades. Vidal desitja realitzar una nova traducció perquè es tractava d'una obra que encara era capaç d' "hablar» al públic decimonònic, ja que aquest tipus de drames de passió i gelosia es representaven sovint, segons l'editor, en la vida real. Es tracta d'una traducció en hendecasíllabs lliures bastant fidel si es tenen en compte les versions del segle precedent (Lafarga 2016: 381). No obstant això, no sorprèn que Llorente realitzara una nova traducció de Zaïre, ni tan sols que traduirà per primera vegada una obra de teatre, perquè s'interessà per aquest gènere en la seua joventut; allò insòlit és que el poeta traduïra una obra del gran enemic de l'Església catòlica. Com que aquesta obra no es va traduir amb la intenció d'escenificar-se, potser fou el context cultural de Zaïre allò que copsà l'atenció de Llorente, o fins i tot pot ser que es tractara d'un repte personal per a donar a l'estampa una versió alternativa de la ja establerta i canònica de García de la Huerta.

El volum de les Fábulas de La Fontaine (1885) és la primera col-laboració de Llorente amb l'editorial Montaner i Simon i anava acompanyat de les belles il-lustracions de Gustave Doré. Contràriament a la pràctica habitual, Llorente tradueix les faules en prosa, la qual cosa indueix a pensar en un encàrrec editorial, ja que és de sobra conegut el que opinava Llorente de la traducció en prosa dels versos. En realitat, a més empreses difícils s'havia enfrontat abans, per exemple amb el Fausto, com per a ser incapaç de traspassar les faules a rima. Llorente opta per la recreació en les traduccions i «conjuga la expresividad con una cuidada prosa que sugiere un destinatario más selecto» (Ozaeta Gálvez 2006: 1780). No obstant això, encara que es tracte de l'única obra de Llorente en prosa, de les Fabulas, se'n va fer diverses reimpressions, que fins

REVISTA VALENCIANA DE FILOLOGIA / I I (20I8) p. 207-24I

IRENE ATALAYA

Teodor Llorente, traductor i creador / 228 
i tot han arribat a l'actualitat, $i$ han esdevingut la seua traducció més reeditada i actual, segurament perquè, a partir de 1980, desaparegueren els drets de reproducció. Un altre motiu pot ser l'escassa nòmina de traductors d'aquesta mena de composicions. També el fet que estiguen escrites en prosa ajuda sens dubte a l'acceptació posterior. A més, el caràcter arcaic en l'imaginari cultural de la faula permet la valorització per part del lector d'un text antic, ja que La Fontaine és sinònim de composició il·lustrada. Per tant, en llegir els textos de Llorente, que tenen un toc del llenguatge decimonònic, el receptor actual de l'obra es transporta al moment de creació de l'original i això constitueix una recepció adient i acceptada.

Don Jaime I el Conquistador del baró de Tourtoulon i Paseo por España de Valérie de Gasparin estan relacionades amb la faceta historiadora de Llorente. Ambdues apareixen sense el nom del traductor. Encara que s'ha pogut comprovar l'autoria de la primera, la segona continua sent un misteri, si bé es tenen indicis que corregué a càrrec del poeta valencià perquè signa el pròleg de l'obra en 1875 i a més en 1869, tot just editada l'obra en francès, es tradueix la part dedicada a València en Las Provincias. ${ }^{7}$ D'altra banda, Llorente esmenta l'obra de la comtessa de Gasparin com a font històrica en l'obra Valencia ${ }^{8}$ de la mateixa manera que la del baró de Tourtoulon. Amb ell, Llorente mantingué una sòlida amistat. Des de l'aparició de l'original en 1863, Teodor assenyalà la importància de l'obra per a la història de València en La Opinión i, anys més tard, en Las Provincias (31.III.1872) anunciava feliçment l'adquisició dels drets de reproducció per la traducció. Efectivament, com avançava, existeix constància del bescanvi que tingué lloc entre ambdós escriptors amb relació a aquesta traducció en els epistolaris de Llorente. El baró ultimava ja les correccions de la seua obra per a enviar-li-la a Llorente, ja que Tourtoulon s'ocupà personalment

7 Per tal d'aprofundir en l'estudi d'aquesta obra, vegeu Atalaya (2016).

8 Obra que s'encabeix en el projecte España. Sus monumentos y artes, su naturaleza e historia, impresa per l'establiment de Daniel Cortezo en dos volums en 1887 i 1889 -encara que en realitat aparegueren en 1888 i 1902, respectivament, segons demostra Roca (2004: 105-106)—, per al qual Llorente ja havia publicat el Libro de los Cantares en la Biblioteca Arte y Letras el 1885.

REVISTA VALENCIANA DE FILOLOGIA / I I (20I8) p. 207-24 I

IRENE ATALAYA

Teodor Llorente, traductor $i$ creador / 229 
de la traducció. Segons sembla, la traducció de l'obra estigué motivada per l'homenatge al rei en Jaume a València el 28 de juliol de $1876 .{ }^{9}$

Com hem destacat suara, aquestes dues obres poden relacionar-se amb Valencia. Sus monumentos y artes. Su naturaleza e historia, ja que la confecció de la mateixa combrega amb els cànons de la tradició decimonònica de llibres de viatge, tal com sosté Roca (2004: 105). Però, no solament coincideix respecte de l'estil, sinó que el destinatari també compleix els requisits d'aquests relats, ja que Llorente no creà aquesta obra per als valencians: «el seu lector ideal és una persona que sovint desconeix els detalls i els costums valencians» (Roca 2004: 105).

Aquestes quatre obres considerades menors, ja que s'allunyen de l'univers estètic del poeta, demostren una vegada més el caràcter polifacètic de Llorente, no solament com a historiador o cronista de viatge, sinó també com a traductor de teatre o, fins i tot, com a traductor d'una acurada prosa quan acara un text poètic.

\section{La pervivència de les traduccions de Llorente}

Si bé les antologies de Llorente, a diferència de les seues obres, no foren mai reeditades pòstumament, les versions que les integraven foren reutilitzades per diversos antòlegs, editors o traductors sobretot en el primer terç del segle xx. Les seues traduccions continuaren vives gràcies a la tasca d'uns altres escriptors que consideraren que els seus poemes seguien d'actualitat. Això demostra alhora que, si uns altres reprenen les versions llorentines, és perquè es parteix del principi que les traduccions no són alienes a un sistema literari i que, per tant, són reclamades per la literatura d'arribada com a pertanyents al mateix sistema literari. No solament hi ha una temptativa d'aquestes noves empreses d'oferir una mostra del panorama poètic estranger com a part del coneixement

9 Sobre aquest esdeveniment, poden consultar-se els treballs de Roca (2009) i Heras Esteban (2000).

REVISTA VALENCIANA DE FILOLOGIA / I I (20I8) p. 207-24 I

IRENE ATALAYA

Teodor Llorente, traductor i creador / 230 
de la literatura d'uns altres països, sinó que també les versions castellanes se sotmeten a la revisió, acceptació o desvinculació d'aquest cànon.

Les traduccions de Llorente seran reutilitzades per diversos autors o estudiosos en obres de diversa índole com ara la de Suárez Capalleja, Estudios sobre Longfellow (1883); Temas de literatura clásica, antigua y moderna para el estudio práctico de la historia literaria, de Navarro Ledesma (1903); Poesías líricas de Schiller, editades per Estelrich (1907-1908) o Canciones de Noche-Buena, de Fernández Shaw (1910-1911). A més, les versions de Llorente travessen l'Atlàntic i apareixen a Colòmbia, segurament gràcies a les edicions de Pascual Aguilar, amb obres com l'editada per Rivas Groot i Soffia, Víctor Hugo en América. Traducciones de ingenios americanos (1889), i la de Torres Mariño Traducciones poéticas de Longfellow (1893). Una vegada mort Llorente, també les seues versions apareixeran fins a la segona meitat del segle $\mathrm{xx}$ en obres de caràcter panoràmic com Antología de líricos ingleses y angloamericanos de Sánchez Pesquera (1915-1924) i en diversos volums de la col·lecció «Las Mejores Poesías Líricas de los Mejores Poetas» de Maristany entre 1920 i 1932, i també en una altra col-lecció argentina, «Los Poetas», que imitava la del traductor català. També hi aparegueren en volums de caràcter didàctic com el de López Barrera, Crítica de traducciones en prosa y en verso (1921), o en les obres d'Eulate Sanjurjo: Vida sentimental de Schiller (1942) i La juventud apasionada de Goethe (1943).

Del Fausto i del Libro de los Cantares, n'hi hagué segones reedicions a començament del segle xx procurades per l'editor Maucci i, fins el 1917, el Fausto llorentí era l'única traducció que circulava per Espanya i serà reeditada a Buenos Aires i a Bogotà durant el segle xx. Evidentment, les noves generacions han tingut la necessitat de retraduir aquestes obres perquè les traduccions envelleixen, encara que ajuden a configurar-ne el cànon. $\mathrm{Si}$, per exemple, en 1882, Fausto era només conegut com un fet aillat en la literatura i per l'òpera de Gounod, allò cert és que la traducció de Llorente n'ajudà al coneixement i èxit a Espanya. Per tant, és important ser conscient de la bretxa diacrònica $\mathrm{i}$ cal considerar els textos de Llorente des d'una perspectiva històrica i cultural i valorar que, en realitat, els traductors que el seguiren no solament han produit

REVISTA VALENCIANA DE FILOLOGIA / I I (20I8) p. 207-24 I

IRENE ATALAYA

Teodor Llorente, traductor $i$ creador / 23 I 
diverses versions de l'original, sinó de la traducció precedent. S'hi observa la importància de les seues versions per al sistema literari espanyol en l'era de l'apogeu de l'antologia traduïda. No obstant això, a partir dels anys trenta, tret de les Fábulas, que tornen a reeditar-se a hores d'ara, allò cert és que assistim a un progressiu oblit de la figura de Llorente com a traductor, la qual cosa pot vincular-se igualment a la seua obra original, que no comença a ser recuperada a València fins els anys huitanta i més aprofundidament al segle XXI amb les recerques de Roca (2004, 2007a y 2007b). A més, cal sospesar igualment el moment històric que Espanya pateix a partir de 1936 i l'exhauriment literari, però també el menysteniment de la figura d'aquest poeta per part de l'esquerra, o la indiferència total de la dreta, en considerar-lo només un escriptor regionalista.

\section{Llorente, poeta traductor o traductor poeta}

La visió de Llorente sobre la creació es reflecteix en la seua traducció, que, alhora, estableix paral-lelismes amb la seua obra de creació original. Molts han estat els poetes que, en la història de la literatura, s'han llançat a traduir uns altres poetes. La llista és àmplia: Nerval, Baudelaire, Mallarmé, Pound, Valéry, J. R. Jiménez, Cernuda... Allò que condueix aquests traductors a submergir-se en l'activitat és l'expansió de les seues estructures i llenguatge poètic com a exercici artístic o com a apropiació d'una estètica estrangera. Així ho confessa Llorente pel que fa a Hugo i Lamartine: « ¿Quería asimilarme la poesía del uno y del otro, y con este objeto, por pura fruición propia, sin ulterior propósito, di en traducir sus versos!» (1906: 5). En 1860 Llorente utilitza la traducció com a exercici per a alliberar la seua veu, sota l'impuls dels pensaments d'un altre (Folkart 2007: 132). Per això mateix, molt sovint la frontera entre la recreació i l'apropiació s'hi presenta difusa i es pot, fins i tot, parlar de robatori (Jiménez 2006: 8). A això es referia Octavio Paz quan advertia dels riscos que corre el poeta traductor, és a dir, quan aquest pren «el poema ajeno como un punto de partida para escribir su poema» (Paz 1990: 20). Tot i això, i encara que ens allunyem del concepte clàssic de traducció, aquest tipus de reescriptura

REVISTA VALENCIANA DE FILOLOGIA / I I (20I8) p. 207-24 I

IRENE ATALAYA

Teodor Llorente, traductor i creador / 232 
o adaptació, versió o imitació o, fins i tot, l'apropiació, és en realitat traducció. No obstant això, anys més tard, Llorente tingué l'oportunitat de recrear poemes anàlegs, que no idèntics, als poemes originals (Paz 1990: 20). Tot això serveix per a avaluar la seua evolució com a traductor, perquè si bé el mètode de paràfrasi i l'adaptació a la mètrica castellana serà la marca de distinció, hi ha en ell una intenció de millora i superació amb el pas dels anys.

Allò cert és que l'activitat creativa de Llorente, ja siga original en castellà o valencià, o en forma de traducció correspon al mateix període. Si, com explica Christine Lombez, els poetes s'han aventurat a traduir, «c'est bien parce que chez eux l'acte d'écrire et l'acte de traduire engagent un même geste de création et s'enrichissent l'un l'autre» (2016: 332). En analitzar una figura complexa com Llorente, cal tenir en compte dues variables: d'una banda, la traducció com a acte de creació i recreació en si mateix, sobretot si es tenen en compte les diverses versions que el poeta procura al llarg dels anys; de l'altra, també els vincles que es puguen establir entre les dues activitats creatives, ja que una de les preguntes que sorgeixen quan acarem un traductor com Llorente són les motivacions que pogueren guiar-lo en el procés, és a dir, ho feia com a aprenentatge literari o com a ferramenta poètica? Tal com Lafarga i Pegenaute assenyalen, ací es qüestiona aleshores:

[...] hasta qué punto las traducciones determinaron su propia producción posterior [la de los poetas-traductores] o si, por el contrario, fue su propia poética personal la que influyó de forma decisiva en el modo de traducir. Esta pregunta es a veces un tanto complicada de analizar, porque muchas veces ambas actividades caminan al mismo paso. (2015b: 9)

Per a Llorente, la traducció fou una forma d'alliberar la seua veu sota l'impuls dels pensaments d'un altre i fou una manera de definir els seu mateix estil. Com que Llorente considera que la traducció de poesia pot realitzar-se en vers i que tan sols pot ser una aproximació, les seues versions s'apropen a la paràfrasi i, per extensió, a la imitació. És evident que el traductor és també escriptor i acara els mateix problemes, cruilles i dubtes que l'autor. Els escriptors coetanis

REVISTA VALENCIANA DE FILOLOGIA / I I (20I8) p. 207-24 I

IRENE ATALAYA

Teodor Llorente, traductor i creador / 233 
feien al·lusió a aquesta doble relació. Cal recordar el que escriu Pérez Galdós en 1883 pel que fa al Fausto: «traducir así es algo tan grande como crear» (Llorente 2013b: 134). Això està relacionat amb el fet que Llorente acare el gènere més cobejat $\mathrm{i}$ temut per excel-lència. La poesia ha estat des de sempre considerada la composició més pura i de més vàlua; si a això s'hi afegeix el trasllat a un altre idioma i que aquest no trenca l'estètica acceptada, sinó que hi conviu i pertany al sistema literari castellà sense modificar els motles preestablerts, l'acceptació, la vàlua i els afalacs no poden ser més que positius. Sense cap mena de dubte, la traducció poètica — que no sempre la traducció de poesia- és un acte de creació. Així ho matisava Iborra Martínez, que explica que el poeta no va traduir mai per encàrrec editorial —almenys si pensem en les seues poesies—, sinó pel desig de voracitat com a lector de versos que era: «los amaba, los sentía, y por esto tenía necesidad de trasladarlos a un idioma más familiar, para poseerlos de una manera más perfecta» (Levante «Suplemento Valencia», 13.11.1959).

No obstant això, la fama de Llorente com a traductor també està motivada pel fet que aquest acompanya el seu treball d'una obra de creació i, com argüeix Gallego Roca (2006: 28), aquesta és la condició sine qua non perquè el nom del poeta romanga en el temps i se salve de l'oblit. Si bé Llorente no publica el seu primer llibre de versos propis en valencià fins al 1885, quan ja havia donat a l'estampa nombroses traduccions, la cosa certa és que en els anys cinquanta ja devia haver començat a crear en castellà, entre 1854 i 1866, encara que la seua producció castellana no es publique fins el 1907, Versos de la juventud, però també en valencià. Datada per Roca en 1855, Llorente escriu la que serà la seua primera composició «L'amor del poeta» (Llorente 2013: 97), és a dir, alhora que les seues traduccions i els seus versos castellans. El triple exercici poètic està relacionat, i per tant, és difícil saber quina de les activitats tingué influència sobre l'altra o quina aparegué en primer lloc. El mateix Llorente assenyala l'influx de Lamartine en la seua poesia "Aparició», com la poesia «Apparition» de les Nouvelles méditations poétiques:

La influencia de Petrarca y Lamartine, els meus autors predilectes en aquells temps, se veu en la poesía á que se referix la present nota, po-

REVISTA VALENCIANA DE FILOLOGIA / I I (20I8) p. 207-24I

IRENE ATALAYA

Teodor Llorente, traductor i creador / 234 
esía que he posat en aquest llibre ronegament pera memória de aquella restauració literaria, y perque han parlat ya d'aquells primers ensaigs los historiadors del renaiximent (Llorente 1885b: 193-194).

Els paral-lelismes entre les seues traduccions i les seues primeres creacions tant en valencià com en castellà són òbvies, sobretot en els anys de joventut (vegeu Atalaya 2017a: 387-398), i els crítics coetanis l'assenyalaren amb relació a les seues versions valencianes, que tingueren un impacte més important en la vida del poeta. Per exemple, Pardo Bazán estableix semblances, però també diferències, entre el seu poema «Testament» (Llorente 2013a: 489) i la seua traducció de Musset «Lucia» (Diversos autors 1906: 182) en la seua columna de La Ilustración Artística (21.08.1911), comparació que també realitza Almela i Vives (Levante «Suplemento Valencia», 03.05.1957).

En general, el poeta valencià confereix més importància a les seues traduccions que a la seua creació original en castellà. Encara que les seues publicacions valencianes arriben més tard, seran igualment de gran vàlua per a ell, per tot allò que representaren aquestes creacions per al renaixement literari de la llengua. Tanmateix, tractant-se del mateix període de creació és lògic pensar que les seues versions en castellà o valencià s'inspiraren en els seus assajos de traducció, perquè també foren les seues primeres lectures. Els poemes llorentins tenen un caràcter clàssic en la forma i beuen del Romanticisme lamartià, que ens reenvia una vegada més a aquesta afinitat estètica. Encara que s'hi veja també l'influx de Heine, Musset, Goethe, Schiller o Hugo, les poesies de Llorente no mostren ni ironia ni desesperació. Per a ell, l'amor, l'estimada, és un ser complementari a la musa sense que ambdues entren en conflicte. El sentiment amorós és tangible i ideal, sense arravataments ni turments com els de Musset o Heine. La natura és un element diví en què troba la pau interior i la fe és un sentiment propi tan profund que pot ser comparat amb l'amor. Dit això, és innegable que la seua posició com a creador de poesia atorgue al poeta traductor un esguard doble sobre l'experiència de l'escriptura i la traducció (Lombez 2016: 29). En aquest sentit, com Yves Bonnefoy, traductor i poeta, confessava: si un traductor «écrit lui aussi, il ne pourra tenir séparée sa traduction de son œuvre propre» (1992: 153-154).

REVISTA VALENCIANA DE FILOLOGIA / I I (20I8) p. 207-24I

IRENE ATALAYA

Teodor Llorente, traductor $i$ creador / 235 
En conclusió, és necessari donar veu als traductors poetes i reconèixer la importància que les traduccions de Llorente tingueren per a tota una generació que s'atansà als romàntics europeus gràcies a la profusa tasca i l'infatigable treball, i reivindicar-ne el paper per al polisistema literari peninsular de la segona meitat del segle xix. Com Gómez de Baquero assenyalava amb motiu de la coronació de Llorente el 1909:

Llorente es $[\ldots]$ una figura de conjunto. Si solo hubiera sido el poeta regional, o el traductor excelente, o el periodista inteligente y culto, o el historiador de Valencia; si a todos esos títulos no se hubiera unido el prestigio de una vida y un carácter moral, $[\ldots]$ le habrían faltado materia y ambiente popular. Cada una de aquellas cualidades ha puesto una hoja de laurel en la corona que Valencia ha ofrecido a su poeta (La España Moderna, 12.1909).

Espere, amb aquest petit esbós, fruit de les meues recerques plasmades en la meua tesi doctoral, haver tornat Llorente al lloc que mereixia en els estudis històrics de la traducció, en què desitge igualment haver pogut contribuir, i m'aventure a definir-lo com un dels traductors poètics més importants del panorama espanyol decimonònic: un traductor per principis i apassionat per la traducció que sabé transmetre-ho als seus contemporanis.

\section{Bibliografia}

Traduccions realitzades per Llorente i reedicions de les seues traduccions

Balaguer, V. (1878) «La muerte de Aníbal», en Tragedias, Madrid, Imprenta de Fortanet, 62-85, <bibliotecadigitalhispanica.bne.es>.

Byron, G. (1863) El corsario, poema de lord Byron, traducido del inglés en verso castellano por D. Vicente Wenceslao Querol \&̋ D. Teodoro Llorente, València, Imprenta de La Opinión, a càrrec de J. Doménech.

- (1929) El corsario. Traducido por Vicente W. Querol \& Teodoro Llorente, ed. Lluís Guarner, Madrid, Los poetas («Los poetas»; any 2, n. 65).

REVISTA VALENCIANA DE FILOLOGIA / I I (20I8) p. 207-24I

IRENE ATALAYA

Teodor Llorente, traductor i creador / 236 
Diversos autors (1875) Leyendas de oro. Poesías de los principales autores modernos, vertidas en rima castellana por Teodoro Llorente, València, Querol y Doménech ( «Biblioteca Selecta»; 5), <http://bivaldi.gva.es/> (4 edicions).

Diversos autors (1876) Amorosas. Poesías de los principales autores modernos puestas en rima castellana por Teodoro Llorente, València, Querol y Doménech («Biblioteca Selecta»; 8), <http://bivaldi.gva.es/> (3 edicions).

Diversos autors (1879) Leyendas de oro. Poesías de los principales autores modernos, vertidas en rima castellana por Teodoro Llorente, $3^{a}$ ed. corr. por el autor y notablemente aum., València, T. Llorente y Cía. editores ( Biblioteca Familiar»).

Diversos autors (1906) Poetas franceses del siglo XIX. Traducción en verso castellano por D. Teodoro Llorente. Edición ilustrada, Barcelona, Montaner y Simón, <http://bivaldi.gva.es/>.

Diversos autors (1908) Leyendas de oro. Poesías de autores modernos vertidas en rima castellana. Segunda serie, València, Imprenta de Vives Mora («Biblioteca Selecta»; 97).

Diversos autors (s. f.) Nueva antología de poetas franceses modernos, trad. Teodor Llorente, inèdita i no localitzada (preparada per a l'editorial F. Granada de Barcelona).

Gasparin, V. de (1875) Paseo por España. Relación de un viaje a Cataluña, Valencia, Alicante, Murcia y Castilla, València, Imprenta de José Doménech, <bibliotecadigitalhispanica.bne.es>; (reed. facsimilar València, Librerías París-Valencia, 1998).

Goethe, J. W. (1882) Fausto. Tragedia, traducida en verso por Teodoro Llorente. Ilustración de A. Liezen Mayer, R. Seitz y A. Schmitz, Barcelona, E. Doménech y Cía., Imprenta de F. Giró («Biblioteca Arte y Letras»), <http://bivaldi.gva.es/>.

- (1905) Fausto. Tragedia de Juan Wolfango Goethe. Primera parte. Nueva edición, revisada por el traductor y seguida de una reseña de la segunda parte, Barcelona, Montaner y Simón (2a edició, 1929).

- (1947) Fausto. Tragedia, trad. Teodor Llorente, Buenos Aires, Sopena Argentina.

- (1952) Fausto. Tragedia, trad. Teodor Llorente, Buenos Aires, Editorial Tor.

- (1986) Fausto. Tragedia, trad. Teodor Llorente, Bogotà, Tercer Mundo.

HeIne, H. (1885) Libro de los Cantares. Traducción en verso, precedida de un prólogo por Teodoro Llorente. Ilustración de P. Thumann, Barcelona, Imprenta de Daniel Cortezo («Biblioteca Arte y Letras»), <http://bivaldi.gva.es/>.

- (1908) Poesías traducidas en verso castellano y precedidas de un prólogo por Teodoro Llorente. Nueva edición corregida y aumentada, Barcelona, F. Granada.

- (1944) Poesías, trad. Teodor Llorente, pròleg d'Agustí Esclasans, Barcelona, Fama.

Hugo, V. (1860) Poesías selectas de Victor Hugo, traducidas por Teodoro Llorente, pròleg de Emilio Castelar, Madrid, Imprenta de Juan Antonio García, <http://bivaldi.gva.es/>.

- (1883) Tres poesías de Víctor Hugo. Traducción de Teodoro Llorente, València, Imprenta de Doménech.

REVISTA VALENCIANA DE FILOLOGIA / I I (20I8) p. 207-24I

IRENE ATALAYA

Teodor Llorente, traductor i creador / 237 
La Fontaine, J. (1885) Fábulas de La Fontaine, ilustradas por Gustavo Doré. Traducción de D. Teodoro Llorente, Barcelona, Montaner y Simón (reed. facsimilar Madrid, Compañía Literaria, 1995).

- (1928) Fábulas de La Fontaine ilustradas por Gustave Doré. Traducido por Teodoro Llorente, Barcelona, Montaner y Simón.

- (1940) Fábulas de La Fontaine. Acompañadas del texto francés e ilustradas con 61 reproducciones de Oudry, trad. Teodor Llorente, Barcelona, Montaner y Simón.

- (1949) Fábulas de La Fontaine ilustradas por Gustave Doré, trad. Teodor Llorente, Mèxic, Editorial Hispano-Americana.

— (1984) Fábulas escogidas, trad. Teodor Llorente, Madrid, Busma («Poesía popular»; 63).

- (1993) Fábulas escogidas, trad. Teodor Llorente, Madrid, M. E. («Clásicos de siempre»; 16).

- (1995) Cien fábulas de Jean de la Fontaine, trad. Teodor Llorente, Madrid, Guillermo Blázquez.

- (2007) Fábulas escogidas, trad. Teodor Llorente, Madrid, EDIMAT.

- (2008) Las fábulas ilustradas por Gustave Doré, trad. Teodor Llorente, Barcelona, Edhasa («Los libros del tesoro»).

Lamartine, A. (1858) Meditaciones poéticas de Alfonso de Lamartine con un prólogo de Antonio Aparisi Guijarro, trad. Teodor Llorente, València, obra inèdita i conservada a la Biblioteca Llorente.

Tourtoulon, C. de (1874) Don Jaime I el Conquistador, rey de Aragón, conde de Barcelona, señor de Montpeller, según las crónicas y documentos inéditos. Traducción autorizada y revisada por el autor, València, Imprenta de José Doménech, 2 vols, <http://bivaldi. gva.es/>, (reed. facsimilar Valencia, Librerías París-Valencia, 1980).

Voltaire (1868) Zaira, tragedia, traducida en verso español por D. Teodoro Llorente, Barcelona, Establecimiento Tipográfico-Editorial de Salvador Manero, 599-618 («Teatro Selecto Antiguo y Moderno, Nacional y Extranjero"; v).

- (1921) Zaira, trad. Teodor Llorente, Buenos Aires, Moro, Tello \& Cía (Teatro Popular; any 3 , núm. 82).

Obres i estudis citats

Atalaya, I. (2016) «Literatura de viajes y su traducción: el caso de Paseo por España (1875) de Valérie de Gasparin", Estudios Románicos, 25: 41-52.

- (2017a) Traducción y creación en la obra de Teodoro Llorente, Barcelona, Universitat de Barcelona (tesi doctoral inèdita).

- (2017b) «Teodoro Llorente y la poesía francesa: una (nueva) antología frustrada», en F. Lafarga (ed.), La traducción fragmentaria: su lugar en antologías y revistas españolas (1898-1936), Madrid, Escolar y Mayo, 159-172.

Blasco Laguna, R. (1984) Estudis sobre la literatura del País valencià (1859-1936), l'Alcúdia, Edicions de l'Ajuntament de l'Alcúdia.

REVISTA VALENCIANA DE FILOLOGIA / I I (20I8) p. 207-24 I

IRENE ATALAYA

Teodor Llorente, traductor i creador / 238 
Bassnett, S.; Lefevere, A. (1990) Translation, History and Culture, Londres-Nova York, Pinter. Bonnefoy, Y. (1992) Entretiens sur la poésie: 1972-1990, París, Mercure de France.

Chesterman, A. (2009) «The Name and Nature of Translator Studies», Hermes, 42: 13-22.

Corbín Llorente, J. T. (2013) «Presentación», en Teodoro Llorente Olivares. Epistolario (1866-1911), ed. Juan Teodoro Corbín Llorente, València, Biblioteca Valenciana Nicolau Primitiu, 15-70.

Cossío, J. M. de (1960) Cincuenta años de poesía española: 1850-1900, Madrid, Espasa Calpe. Delisle, J. (1999) Portraits de traducteurs, Ottawa, Presses de l'Université d'Ottawa.

Folkart, B. (2007) Second Finding. A Poetics of Translation, Ottawa, University of Ottawa Press.

Genette, G. (1987) Seuils, París, Éditions du Seuil.

Heine, H. (1885) El cancionero, trad. Juan Antonio Pérez Bonalde, Nova York, s. i.

Heras Esteban, H. de las (2000) «El monumento al rey Jaime I en la ciudad de Valencia», Ars Longa, 9: 161-167. <http://roderic.uv.es/>.

Jiménez, J. R. (2006) Música de otros. Traducciones y paráfrasis, ed. Soledad González Ródenas, Barcelona, Galaxia Gutenberg-Círculo de Lectores.

LAfarga, F. (1998) «El Victor Hugo romántico en la España realista», en E. Miralles \& L. F. Díaz Larios (eds.), Del Romanticismo al Realismo. Actas del I Coloquio de la Sociedad de Literatura Española del Siglo XIX, Barcelona, Universitat de Barcelona, 249-256.

— (2000) «Teodoro Llorente y la traducción», Anuari de Filologia, XXII (10): 69-75.

- (2001) «Teodoro Llorente, traductor y antólogo de poesía francesa», en L. Pegenaute (ed.), La traducción en la Edad de Plata, Barcelona, PPU, 157-169.

- (2014) «Poetas franceses del siglo XIX, en la traducción de Teodoro Llorente (1906)». Biblioteca Virtual Miguel de Cervantes, <http://www.cervantesvirtual.com/>.

— (2016) «Teodoro Llorente: obra traducida y actividad literaria de un poeta-traductor», en F. Lafarga \& L. Pegenaute (eds.), Autores traductores en la España del siglo XIX, Kassel, Reichenberger, 368-389.

Lafarga, F.; Pegenaute, L. (2015a) «Historiografía de la traducción», en P. Aullón de Haro (ed.), Historiografía y Teoría del Pensamiento, la Literatura y el Arte, Madrid, Clásicos Dykinson, 257-292.

- (ed.) (2015b) Creación y traducción en la España del siglo XIX, Berna, Peter Lang.

- (ed.) (2016) Autores traductores en la España del siglo XIX, Kassel, Reichenberger.

Llorente, T. (1882) «Carta que puede servir de prólogo para esta traducción. A Vicente W. Querol», en J. W. Goethe, Fausto. Tragedia. Primera parte, traducida en verso por Teodoro Llorente, Barcelona, E. Domenech y Cía, Imprenta de F. Giró («Biblioteca Arte y Letras»), I-XXIv, <http://bivaldi.gva.es/>.

- (1885a) «Enrique Heine y su Libro de los Cantares» en H. Heine, Libro de los Cantares, traducción en verso de Teodoro Llorente, Barcelona, Imprenta de Daniel Cortezo, VIILIII («Biblioteca Arte y Letras»), <http://bivaldi.gva.es/>.

REVISTA VALENCIANA DE FILOLOGIA / I I (20I8) p. 207-24I

IRENE ATALAYA

Teodor Llorente, traductor i creador / 239 
- (1885b) «Notes», en T. Llorente, Llibret de versos, València, Teodoro Llorente y Cía. editores, 193-198, <http://bivaldi.gva.es/>.

- (1906) «Proemio», en Diversos autors, Poetas franceses del siglo XIX, traducido por Teodoro Llorente, Barcelona, Montaner y Simón, 5-9, <http://bivaldi.gva.es/>.

- (1908) «Al lector», en Diversos autors, Leyendas de oro. Poesías de autores modernos vertidas en rima castellana. Segunda Serie, València, Librería Aguilar, v-VI («Biblioteca Selecta»; 97).

- (1928) Epistolari Llorente. Cartes de llevantins (1861-1900), ed. Teodor Llorente Falcó, Barcelona, Biblioteca Balmes, vol. I, <http://www.cervantesvirtual.com/>.

- (1930) Epistolari Llorente. Cartes de llevantins (1901-1911), ed. Teodor Llorente Falcó, Barcelona, Biblioteca Balmes, vol. II, <http://www.cervantesvirtual.com/>.

- (1936) Epistolari Llorente. Suplement a les cartes de llevantins. Cartes de Llorente, ed. Teodor Llorente Falcó, Barcelona, Biblioteca Balmes, vol. III, <http://www.cervantesvirtual.com/>.

- (1983) Poesia valenciana completa, ed. Lluís Guarner, València, Edicions Tres i Quatre.

- (2013a) Obra valenciana completa, ed. Rafael Roca, València, Acadèmia Valenciana de la Llengua.

- (2013b) Teodoro Llorente Olivares. Epistolario (1866-1911), ed. Juan Teodoro Corbín Llorente, València, Biblioteca Valenciana Nicolau Primitiu.

- (2016) Poesies i proses valencianes, ed. Rafael Roca, València, Institució Alfons el Magnànim.

Lombez, C. (2016) La seconde profondeur. La traduction poétique et les poètes traducteurs en Europe au xxe siècle, París, Les Belles Lettres.

Martino, P. (2011a) «Libro de los Cantares, de H. Heine, en la traducción de Teodoro Llorente (1885)», en F. Lafarga \& L. Pegenaute (ed.), Cincuenta estudios sobre traducciones españolas, Berna, Peter Lang, 339-344.

- (2011b) «Poesías de H. Heine en la traducción de Teodoro Llorente (1908)», en F. Lafarga \& L. Pegenaute (ed.), Cincuenta estudios sobre traducciones españolas, Berna, Peter Lang, 351-360.

Navarro Reverter, J. (1909): Teodoro Llorente, su vida y sus obras. Florilegio de sus poesias. Barcelona, F. Granada, <http://bivaldi.gva.es>.

Ozaeta, M. R. (2006) «La traducción del espacio denominativo de La Fontaine», en J. L. Arráez Llobregat \& Á. Sirvent Ramos (ed.), Espacio y texto en la cultura francesa. Espace et texte dans la culture française, Alacant, Universitat d'Alacant, vol. 3, 1769-1784.

PAgEARD, R. (1958) Goethe en España, Madrid, CSIC.

Palenque, M. (1990) El poeta y el burgués: poesía y público, 1850-1900, Sevilla, Alfar. Paz, O. (1990) Traducción: literatura y literalidad, Barcelona, Tusquets, 3a edició.

Pegenaute, L. (2004) «La época realista y el Fin de siglo», en F. Lafarga \& L. Pegenaute (ed.), Historia de la traducción en España, Salamanca, Ambos Mundos, 397-478.

REVISTA VALENCIANA DE FILOLOGIA / I I (20I8) p. 207-24I

IRENE ATALAYA

Teodor Llorente, traductor i creador / 240 
- (2015) «Del Romanticismo inglés a la Renaixença valenciana: Byron traducido por Vicente W. Querol y Teodoro Llorente (1863)», en F. Lafarga \& L. Pegenaute (ed.), Varia lección de traducciones españolas, Madrid, Ediciones del Orto, 131-142.

Peña Martín, S. (1997) «El traductor en su jaula: hacia una pauta de análisis de traducciones», en E. Morillas \& J. P Arias (ed.), El papel del traductor, Salamanca, Colegio de España, 19-58.

Pyм, A. (2009): «Humanizing Translation History», Hermes, 42: 23-48.

RocA, R. (2004) Teodor Llorente, el darrer patriarca, Alzira, Bromera.

- (2007a) Teodor Llorente i la Renaixença valenciana, València, Institució Alfons el Magnànim.

- (2007b) Teodor Llorente, líder de la Renaixença valenciana, València, Universitat de València.

- (2007c) «Teodor Llorente, escriptor valencià», Caplletra. Revista Internacional de Filologia, 43 (tardor): 9-37, <https://ojs.uv.es/index.php/caplletra/>.

- (2009) «Teodor Llorente i el certamen en honor de Jaume I (1876)», en J. Massot i Montaner (ed.), Miscel-lània Joaquim Molas, Barcelona, Abadia de Montserrat, vol. 4, 95-121.

— (2012) «L'epistolari entre Teodor Llorente i Vicent W. Querol (1876-1889)», en R. Roca (ed.), Teodor Llorente, cent anys després, Alacant, Institut Interuniversitari de Filologia Valenciana, 209-288.

- (2013a) «El poeta de Valencia», en T. Llorente, Obra valenciana completa. Estudi i edició crítica a cura de Rafael Roca Ricart, València, Acadèmia Valenciana de la Llengua, 27-89.

- (2013b) «Les traduccions catalanes de Teodor Llorente: gènesi i model lingüístic», en E. Casanova \& C. Calvo Rigual (ed.), Actas del XXVI Congreso Internacional de Lingüística y de Filología Románicas, Berlín-Boston, De Gruyter, vol. viII, 457-468, <http:// roderic.uv.es/>.

SAla Giner, D. (2011) Teodor Llorente i Olivares, la coherència d'una vida, València, Lo Rat Penat.

REVISTA VALENCIANA DE FILOLOGIA / I I (20I8) p. 207-24 I

IRENE ATALAYA

Teodor Llorente, traductor $i$ creador / $24 \mathrm{I}$ 


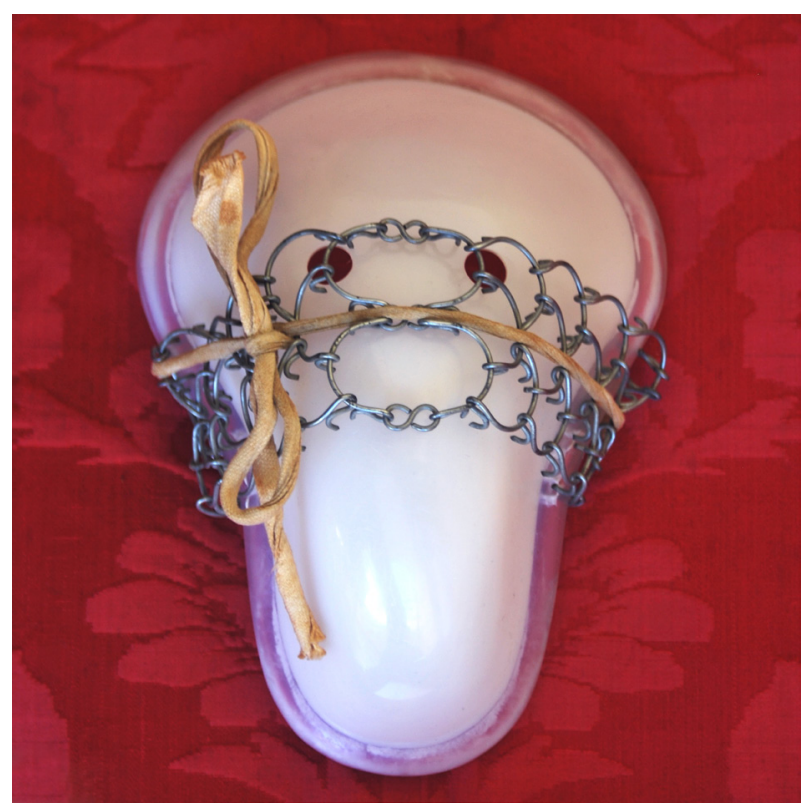

Joan Millet

Cilici, 2018

Tècnica mixta 